\title{
MICROENCAPSULATION OF OLIVE LEAF EXTRACT BY SPRAY DRYING
}

\author{
A. Dobrinčić*, L. TuĐen, M. Repajić, I. Elez Garofulić, Z. Zorić, \\ V. Dragović-Uzelac and B. LevaJ \\ Faculty of Food Technology and Biotechnology, University of Zagreb, Pierottijeva 6, 10000 Zagreb. Croatia
}

(Received: 6 April 2020; accepted: 24 June 2020)

\begin{abstract}
The aim of this research was to obtain a high value powder of olive leaf extract (OLE) rich in polyphenols by spray drying. Since carrier, polyphenols/carrier ratio, and inlet temperature could have an impact on process yield and polyphenol retention, to define the most promising drying conditions for OLE experiment with gallic acid model solutions (GAS) was conducted. Influence of carrier type (maltodextrin, inulin, gum arabic, and their two-component blends), polyphenols/carrier ratio, and temperature on process yield of spray dried GAS was examined, and for each carrier the most promising temperature and ratio were selected. Optimal temperature for all GAS samples was $150{ }^{\circ} \mathrm{C}$, and optimal gallic acid/carrier ratio for samples with inulin or gum arabic was 3:1, while for all other combinations it was 5:1. In OLE powder produced under these conditions, polyphenol content and physical properties (rehydration, bulk density) were determined. Mixture of maltodextrin and gum arabic resulted in the highest OLE product yield (54.48\%) and the highest polyphenol retention $(56.50 \%)$ obtaining good physical properties (bulk density $=0.31 \mathrm{~g} \mathrm{ml}^{-1}$, rehydration time $=98 \mathrm{~s}$ ), while use of inulin resulted in the lowest yield (32.71\%), polyphenol retention $(28.24 \%)$, bulk density $\left(0.25 \mathrm{~g} \mathrm{ml}^{-1}\right)$, and the highest rehydration time (140 s).
\end{abstract}

Keywords: olive leaf, polyphenols, spray drying, maltodextrin, inulin, gum arabic

Olive (Olea europaea L.) leaves are agricultural and industrial waste, and they are considered as cheap, renewable, and rich sources of polyphenols (Ben SalaH \& ABDelmeleK, 2012), compounds that possess antioxidant activity and are known to have a positive impact on human health. Due to their antioxidant, antimicrobial, antiviral, and anti-inflammatory properties (BEN SALAH \& ABDELMELEK, 2012), polyphenols have the potential to replace undesirable synthetic antioxidants in the food industry, as well as in the pharmaceutical and cosmetic industries. However, there are some shortcomings in polyphenols application, such as poor solubility in water and sensitivity to environmental factors like light, oxygen, temperature, and enzymes (MUNIN \& EDWARDS-LÉvy, 2011), which may cause the loss of their basic function. In order to preserve their biochemical functions, microencapsulation process could be applied. The most commonly used microencapsulation technique is spray drying, where carrier (usually polysaccharide matrix) is used with the main purpose to lower hygroscopicity and thermoplasticity of the extract with no impact on the quality of obtained powder (KosARAJU et al., 2006) as well as its ability to protect the present bioactive compounds. Generally, maltodextrin and gum arabic are frequently used carriers in plant extracts' and fruit juices' spray drying due to their properties that enable them to obtain good quality powders (TuPUNA et al., 2018). Oligosaccharide inulin as potential carrier is in special interest due to its prebiotic properties, too (SAÉNZ et al., 2009). Several studies dealt with spray drying of olive leaf extract (OLE) so far, but with no primary focus on the selection of

\footnotetext{
* To whom correspondence should be addressed.

E-mail: adobrincic@pbf.hr
} 
the most suitable carrier for OLE spray drying, e.g., KOSARAJU and co-workers (2006) used chitosan, KIRITSAKIS and co-workers (2017) maltodextrin, URZÚA and co-workers (2017) inulin, and GonZÁLEZ and co-workers (2018) sodium alginate. With the assumption that type of carrier has an impact on polyphenols content and quality parameters of powder obtained by spray drying, this research aimed to evaluate the influence of carrier type (maltodextrin, inulin, gum arabic) and its two-component blends as well as polyphenols/carrier ratio (3:1 and 5:1) and drying temperature $\left(120,150\right.$, and $\left.180^{\circ} \mathrm{C}\right)$ on product yield of spray dried gallic acid model solutions (GAS), and based on the obtained results to evaluate the effect of selected ratio and temperature on quality parameters and polyphenol content of spray dried OLE powder.

\section{Materials and methods}

\subsection{Samples and chemicals}

Olive leaves, cv. Cipressino, were collected in Split area (Croatia), air dried at room temperature for 4 days, milled with electric grinder, and stored in the dark at $4{ }^{\circ} \mathrm{C}$ until extraction. Gallic acid (GA) and maltodextrin (MD) DE 13-17 were purchased from SigmaAldrich (St. Louis, USA), gum arabic (AG) from Acros Organics (New Jersey, USA), inulin (IN) from Orafti HSI (Beneo, Germany), and 96\% ethanol from Gram-mol doo (Zagreb, Hrvatska).

\subsection{Pressurised liquid extraction (PLE)}

Extraction of olive leaves was performed using an accelerated solvent extractor (ASE 350, Dionex, Sunnyvale, USA) with distilled water as extraction solvent at conditions as follows: 3 extraction cycles with $5 \mathrm{~min}$ of static time of each cycle at constant temperature of $100^{\circ} \mathrm{C}$. Obtained olive leaf extract (OLE) contained 3.79\% dry matter and $35.6 \mathrm{mg}$ total polyphenols $\left(\mathrm{g}^{-1}\right.$ d.w. $)$. OLE was stored at $+4{ }^{\circ} \mathrm{C}$ in darkness prior to spray drying.

\subsection{Spray drying}

GAS and OLE were sprayed dried on a laboratory scale spray dryer SD 06 (Labplant, North Yorkshire, UK). Spray drying process of GAS was carried out with air flow of $3.5 \mathrm{~m} \mathrm{~s}^{-1}$ by using three different carriers (MD, IN, AG), three 50:50 mixtures of these carriers (MDIN, MDAG, INGA) in two different GA:carrier ratios (3:1 and 5:1), and three inlet temperatures $\left(120,150\right.$, and $\left.180^{\circ} \mathrm{C}\right)$. GA was employed as the typical polyphenol, often used as a standard for determination of total polyphenols content, to simplify the procedure in this research. Spray drying of OLE was carried out afterwards, under determined optimal conditions. The feed solutions $(300 \mathrm{ml})$ were prepared by dissolving GA in ethanol $(96 \%)$ and by mixing with the previously prepared aqueous solution of the carrier, with respect to defined GA:carrier ratio, or by dissolving defined mass of carrier in OLE. The volume of $300 \mathrm{ml}$ OLE contained $1.7 \mathrm{~g}$ total polyphenols and $11.37 \mathrm{~g}$ dry matter prior the carrier addition. All powders were stored in dark containers at $+4{ }^{\circ} \mathrm{C}$ until analysis.

\subsection{Total polyphenols content determination}

Total polyphenols (TP) content was determined in OLE immediately after extraction and in GAS and OLE powders after dissolution $(50 \mathrm{mg})$ in distilled water $(2 \mathrm{ml})$ by Folin-Ciocalteu 
method as described by AHMAD-QASEM and co-workers (2013). All measurements were done in duplicate and results were expressed as $\mathrm{mg}$ of gallic acid equivalents (GAE) per g of dry weight.

\subsection{Product yield}

Product yield of GAS powders was calculated as the ratio of the produced GAS powder mass (g) and sum of the GA and carrier mass (g) in the feed solution. Product yield of OLE powder was calculated as the ratio of the produced OLE powder mass $(\mathrm{g})$ and sum of the carrier mass (g) and dry matter content $(\mathrm{g})$ of $300 \mathrm{ml}$ of OLE.

\subsection{Microencapsulation efficiency}

Microencapsulation efficiency of TP from OLE was calculated as the ratio of TP content in the obtained powder and TP content in the extract subjected to spray drying (PAINI et al., 2015).

\subsection{Bulk density}

Bulk density $\left(\mathrm{g} \mathrm{ml}^{-1}\right)$ was determined by adding $2 \mathrm{~g}$ of OLE powder into $10 \mathrm{ml}$ graduated cylinder and holding the cylinder on a vortex vibrator for $1 \mathrm{~min}$. The ratio of the powder mass and the volume occupied in the cylinder determines the bulk density value (Goula \& AdAmopoulos, 2010).

\subsection{Rehydration}

The rehydration of the powder was carried out by adding $2 \mathrm{~g}$ of the powder to $50 \mathrm{ml}$ of distilled water at $26^{\circ} \mathrm{C}$. The mixture was agitated in a $100 \mathrm{ml}$ glass beaker with a magnetic stirrer at 880 r.p.m., using a stirring bar $(2 \mathrm{~mm} \times 7 \mathrm{~mm})$. The time required for the powder to be completely rehydrated was recorded (Goula \& ADAMOPOULOS, 2010).

\subsection{Statistical analysis}

The experimental design and statistical analysis were done using STATISTICA v. 8 software (StatSoft Inc., Tulsa, USA). Obtained results were analysed by multivariate analysis of variance (MANOVA) and marginal means were compared with Tukey's HSD multiple comparison test. The significance level for all tests was $\alpha \leq 0.05$.

\section{Results and discussion}

\subsection{Product yield}

In spray drying, adhesiveness of the powder and deposition on the drying chamber walls are the main problems that lead to undesirable lower product yield (Yousefr et al., 2011). However, losses could be reduced by selecting the adequate carrier and optimal process parameters. To define the most promising drying conditions for OLE spray drying, experiment with GAS was conducted, in which influence of carrier, GA/carrier ratio, and temperature on product yield were examined. 
For GAS, type of carrier and GA:carrier ratio had a significant $(\mathrm{P} \leq 0.05)$ influence on product yield in contrast to temperature (Fig. 1). The lowest average yield $(28.66 \%)$ was achieved with IN, while the highest (43.72\%) yield was obtained with INAG followed by MDAG (41.64\%). Since GA/carrier ratio and temperature did not have a unique effect on product yield for all carriers, as they depend on chemical composition of the carrier, each carrier was analysed individually, and the highest values achieved, regardless if there was a statistically significant difference, were selected for OLE spray drying. Higher product yield was obtained with 5:1 GA:carrier ratio for samples with MD, MDAG, MDIN, and INAG, while in samples with IN and AG, higher yield was obtained with 3:1 GA:carrier ratio. By increasing the concentration of a carrier, viscosity of the mixture is increased as well as the dry matter content, so more solid particles are available for a contact with drying chamber wall and their possibility to stick on it is higher, which could possibly lead to a reduced product yield (TONON et al., 2008). KRISHNAIAH and co-workers (2012) also confirmed that higher addition of carriers (MD and $\kappa$-carrageenan) does not always leads to more successful drying, while YOUSEFI and co-workers (2011) described a positive effect of higher carrier (MD, AG, waxy starch) amount. Such opposite behaviour of carrier amount on product yield was probably due to its different chemical structure, which could probably explain the adverse results found in the literature. Furthermore, higher carrier amount can enhance the production cost and possibly have negative impact on product taste, which can result in consumers' disapproval (VIDović et al., 2014). The same pattern that was applied to select suitable ratio, was used for temperature selection. Regardless of statistical insignificance, generally the highest yield was achieved at $150^{\circ} \mathrm{C}$, which was used in the further experiments. Similarly, PAINI and co-workers (2015) observed that temperatures below $130{ }^{\circ} \mathrm{C}$ can cause formation of moisture on the drying chamber walls, while temperatures above $160{ }^{\circ} \mathrm{C}$ can lead to a major polyphenols degradation. To examine polyphenols retention, microencapsulation efficiency of GAS was also determined (data not shown), and there was a statistically significant $(\mathrm{P}<0.05)$ strong positive correlation $(\mathrm{r}=0.86)$ between product yield and microencapsulation efficiency.

Table 1. Process yield (\%), efficiency (\%), total polyphenol content ( $\left.\mathrm{mg} \mathrm{g}^{-1} \mathrm{~d} . \mathrm{w}.\right)$, bulk density $\left(\mathrm{g} \mathrm{ml}^{-1}\right)$, and rehydration time (s) of OLE powders produced with different carriers

\begin{tabular}{lccccc}
\hline $\begin{array}{l}\text { Carrier/ } \\
\text { temperature/ } \\
\text { polyphenols: } \\
\text { carrier }\end{array}$ & $\begin{array}{c}\text { Product yield } \\
(\%)\end{array}$ & $\begin{array}{c}\text { Efficiency } \\
(\%)\end{array}$ & $\begin{array}{c}\text { Total polyphenol } \\
\text { content } \\
\left(\mathrm{mg} \mathrm{g}^{-1} \mathrm{~d} . \mathrm{w} .\right)\end{array}$ & $\begin{array}{c}\text { Bulk } \\
\text { density } \\
\left(\mathrm{g} \mathrm{m}^{-1}\right)\end{array}$ & $\begin{array}{c}\text { Rehydration } \\
(\mathrm{s})\end{array}$ \\
\hline $\mathrm{MD} / 150 / 5: 1$ & $37.40 \pm 2.65^{\mathrm{a}, \mathrm{b}}$ & $31.20 \pm 1.54^{\mathrm{a}}$ & $124.32 \pm 4.89^{\mathrm{a}}$ & $0.32 \pm 0.06^{\mathrm{a}}$ & $81 \pm 5^{\mathrm{b}, \mathrm{c}}$ \\
$\mathrm{IN} / 150 / 3: 1$ & $32.71 \pm 1.94^{\mathrm{a}}$ & $28.24 \pm 1.25^{\mathrm{a}}$ & $128.68 \pm 5.32^{\mathrm{a}}$ & $0.25 \pm 0.02^{\mathrm{a}}$ & $140 \pm 9^{\mathrm{e}}$ \\
$\mathrm{AG} / 150 / 3: 1$ & $50.34 \pm 3.61^{\mathrm{b}}$ & $52.90 \pm 3.87^{\mathrm{b}}$ & $121.90 \pm 5.84^{\mathrm{a}}$ & $0.37 \pm 0.05^{\mathrm{a}}$ & $134 \pm 6^{\mathrm{d}}$ \\
$\mathrm{MDIN} / 150 / 5: 1$ & $39.97 \pm 2.38^{\mathrm{a}, \mathrm{b}}$ & $33.81 \pm 2.59^{\mathrm{a}}$ & $126.07 \pm 6.46^{\mathrm{a}}$ & $0.35 \pm 0.05^{\mathrm{a}}$ & $58 \pm 4^{\mathrm{a}, \mathrm{b}}$ \\
$\mathrm{MDAG} / 150 / 5: 1$ & $54.48 \pm 4.21^{\mathrm{b}}$ & $56.50 \pm 4.56^{\mathrm{b}}$ & $130.10 \pm 7.41^{\mathrm{a}}$ & $0.31 \pm 0.03^{\mathrm{a}}$ & $98 \pm 6^{\mathrm{c}}$ \\
$\mathrm{INAG} / 150 / 5: 1$ & $41.08 \pm 2.98^{\mathrm{a}, \mathrm{b}}$ & $54.90 \pm 2.62^{\mathrm{b}}$ & $128.00 \pm 4.28^{\mathrm{a}}$ & $0.36 \pm 0.08^{\mathrm{a}}$ & $42 \pm 4^{\mathrm{a}}$ \\
\hline
\end{tabular}

MD: maltodextrin; IN: inulin; AG: gum arabic; MDIN: maltodextrin+inulin; MDAG: maltodextrin+gum arabic; INAG: inulin+gum arabic

Values with different letters are statistically different at $\mathrm{P} \leq 0.05$

$\dagger$ : Statistically significant variable at $\mathrm{P} \leq 0.05$

: Statistically insignificant variable at $\mathrm{P} \leq 0.05$

Acta Alimentaria 49, 2020 


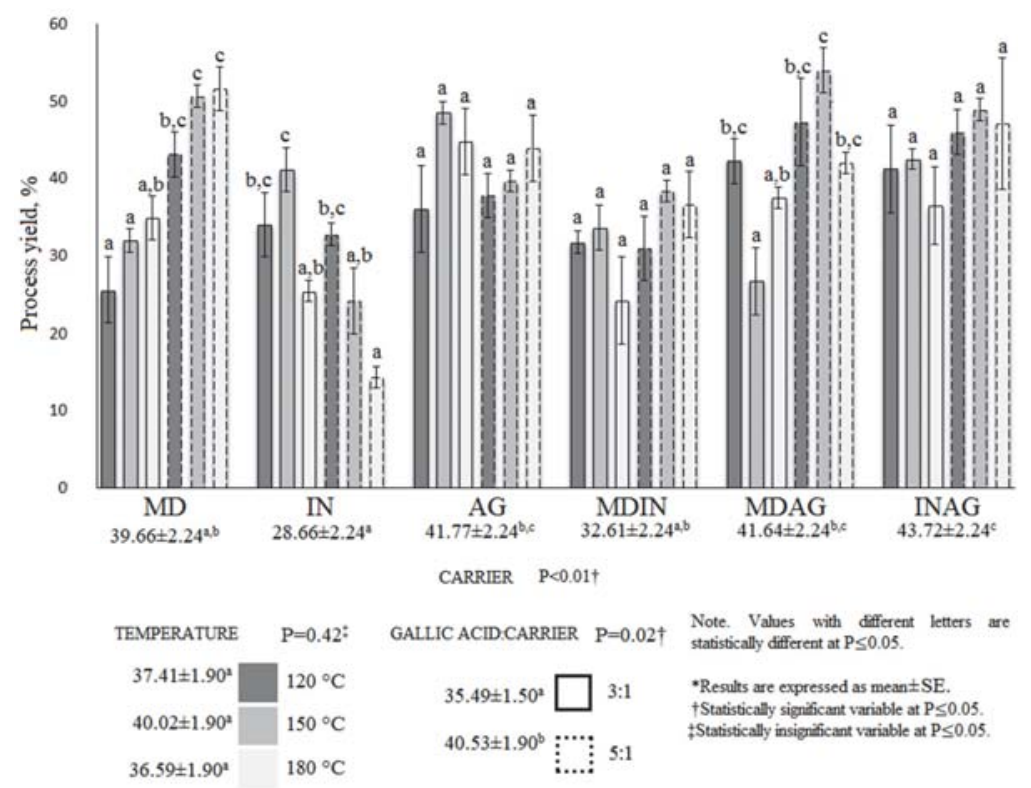

Fig. 1. Influence of various spray drying parameters on process yield (\%) of GAS powders (MD: maltodextrin; IN: inulin; AG: gum arabic; MDIN: maltodextrin+inulin; MDAG: maltodextrin+gum arabic; INAG: inulin+gum arabic)

After GAS product yield evaluation, spray drying of OLE was performed under the established most favourable conditions for each carrier (Table 1). Yield of $32.71 \%$ was achieved by using IN as carrier followed by MD and MDIN, while all samples with AG had higher yields. Only powders produced with AG and MDAG had yields higher than 50\%, which is considered a minimum for successful drying (VIDOvić et al., 2014). QUIRINO LACERDA and co-workers (2016) also achieved the lowest yield by using IN (22.4\%) in spray drying of jussara pulp compared to MD (38.8\%), MDIN (39.8\%), and sodium octenyl succinate starch $(49.3 \%)$.

\subsection{Microencapsulation efficiency and total polyphenols of OLE}

TP contents of OLE powders are shown in Table 1. There was no statistically significant difference between carriers. Microencapsulation efficiency is a useful factor for evaluating the degradation and oxidation of polyphenols that could occur during spray drying. Capability of the carriers to preserve the encapsulated molecules is linked to their chemical structure. IN is a fructooligosaccharide composed of fructose units with $\beta(1,2)$ links to glucose at the end of the chain (PAZ et al., 2017), while MD is a hydrolysed short chain starch that acts as a barrier against oxygen but has a low emulsification and film-forming capacity (TUPUNA et al., 2018). IN application resulted in the lowest microencapsulation efficiency of TP from OLE (28.24\%) followed by MD (31.2\%) and their mixture $(33.81 \%)$ similar to the product yield results. Likewise, IN was less effective than MD (14.6\%), and their mixture $(20 \%)$ in jussara pulp juice encapsulation of anthocyanins (QUIRINO LACERDA et al., 2016) confirmed that a single carrier cannot always provide all the requirements for the succeseful drying, thus a 
mixture of carriers is often used (BEDNARSKA \& JANISZEWSKA-TURAK, 2020). Microencapsulation efficiencies were much higher in all three samples with AG, which is also in accordance with the results for product yield. AG can interact with both hydrophilic and hydrophobic segments of the molecule, because it is formed by a ramified carbohydrate chain and a small amount of glycoproteins linked by covalent bonds. For that reason, AG is compatible with a great variety of polymers, it is an excellent emulsifying agent in a wide $\mathrm{pH}$ range, and it has a great film forming capacity, which allows better preservation of the encapsulated molecule (TuPunA et al., 2018).

\subsection{Bulk density}

Bulk density measurement of herbal extract powders is very important, since the most common application of such powders is in form of capsules or tablets, the volume of which is limited (VIDović et al., 2014). It is defined as the mass of particles divided by the total volume they occupy, and apart from the particles volume, total volume includes the space between them. Heavier powder will fill the space between the particles more easily, so it will occupy less volume and have a higher bulk density. Bioactive compounds in the OLE powder are prone to oxidation, so if the area between the particles is larger, higher oxygen concentration is available, which causes degradative changes and reduces the bioactive properties of the produced powders (ToNON at al., 2010). For that reason, as well as for reduced packaging and shipping costs, higher bulk density is a desirable property of spray dried powders. Even though not statistically different $(\mathrm{P} \geq 0.05)$, the lowest bulk density of OLE powder was achieved with IN, and it was $0.25 \mathrm{~g} \mathrm{ml}^{-1}$, while the highest bulk density of $0.37 \mathrm{~g} \mathrm{ml}^{-1}$ was reached with AG. The lowest (IN) and the highest (AG) bulk densities were achieved at 3:1 polyphenols:carrier ratio, indicating there is no clear connection between bulk density and polyphenols:carrier ratio due to the difference in the carriers' chemical structures. This is supported by Yousefr and co-workers (2011) with MD, AG, and waxy starch, while PAINI and co-workers (2015) and VIDOVIĆ and co-workers (2014) stated that higher carrier (MD) concentration led to lower bulk density. Contrarily, CAI and CORKE (2000) reported that bulk density increased with higher carrier (MD, native and modified starch) concentration.

\subsection{Rehydration}

Rehydration is measured as the time it takes for the dried powder to be visually completely rehydrated. It is the ability of the powder to overcome the surface tension between powder and water. In order to achieve lower rehydration time, high porosity or large pores for bigger particles are desirable (A-Sun et al., 2016). Rehydration time of OLE powder produced with IN was the longest $-140 \mathrm{~s}$, followed by $134 \mathrm{~s}$ with AG (Table 1). However, combination of IN and AG resulted with the shortest rehydration time ( $42 \mathrm{~s}$ ). Only OLE powders produced with IN and AG had polyphenols:carrier ratio of 3:1, indicating that higher concentration of carrier led to higher rehydration time. Similarly, A-Sun and co-workers (2016) found that increase of MD concentrations led to a significant increase in rehydration time. The reason is that the carrier acts as a bulking agent that affects porous structure, making less porous powders, and the consequence is longer rehydration time. 


\section{Conclusions}

Production of a high-quality powder along with maintaining its natural antioxidants is a main challenge during spray drying of plant extracts. Present study confirmed the importance of appropriate carrier type and polyphenols:carrier ratio along with the temperature applied during spray drying of OLE. Spray drying conditions that maintained genuine olive leaf polyphenols involved the use of $\mathrm{MDAG}$ at $150^{\circ} \mathrm{C}$ and 5:1 polyphenols:carrier ratio, resulting in the highest product yield (54.48\%), the highest polyphenol retention $(56.50 \%)$, and good physical properties of obtained powder (bulk density $=0.31 \mathrm{~g} \mathrm{ml}^{-1}$, rehydration time $=98 \mathrm{~s}$ ), which could be further used in various food applications and pharmaceuticals.

This work was supported by the project "Bioactive molecules of medical plant as natural antioxidants, microbicides and preservatives" (KK.01.1.1.04.0093), co-financed by the Croatian Government and the European Union through the European Regional Development Fund - the Competitiveness and Cohesion Operational Programme (KK.01.1.1.04.).

\section{References}

Ahmad-Qasem, M.H., Cánovas, J., Barrajón-Catalán, E., Micol, V., Cárcel, J.A. \& García-Pérez, J.V. (2013): Kinetic and compositional study of phenolic extraction from olive leaves (var. Serrana) by using power ultrasound. Innov. Food Sci. Emerg., 17, 120-129.

A-Sun, K., Thumthanaruk, B., Lekhavat, S. \& Jumnongpon, R. (2016): Effect of spray drying conditions on physical characteristics of coconut sugar powder. Int. Food Res. J., 23, 1315-1319.

BEDNARSKA, M.A. \& JANISZEWSKA-TuRAK, E. (2020): The influence of spray drying parameters and carrier material on the physico-chemical properties and quality of chokeberry juice powder. J. Food Sci. Tech., 57, 564-577.

Ben Salah, M. \& AbdelmeleK, H. (2012): Study of phenolic composition and biological activities assessment of olive leaves from different varieties grown in Tunisia. Med. Chem., 2, 107-111.

CAI, Y.Z. \& CoRke, H. (2000): Production and properties of spray-dried Amaranthus betacyanin pigments. J. Food Sci., 65, 1248-1252.

González, E., Gómez-Caravaca, A.M., Giménez, B., Cebrián, R., Maqueda, M., ... \& Robert, P. (2018): Evolution of the phenolic compounds profile of olive leaf extract encapsulated by spray-drying during in vitro gastrointestinal digestion. Food Chem., 279, 40-48.

Goula, A.M. \& Adamopoulos, K.G. (2010): A new technique for spray drying orange juice concentrate. Innov. Food Sci. Emerg., 11, 342-351.

Kiritsakis, K., Goula, A.M., Adamopoulos, K.G. \& Gerasopoulos, D. (2017): Valorization of olive leaves: Spray drying of olive leaf extract. Waste Biomass Valori., 9, 619-633.

Kosaraju, S.L., D'Ath, L. \& Lawrence, A. (2006): Preparation and characterisation of chitosan microspheres for antioxidant delivery. Carbohyd. Polym., 64, 163-167.

Krishnaiah, D., Sarbatly, R. \& Nithyanandam, R. (2012): Microencapsulation of Morinda citrifolia L. extract by spray-drying. Chem. Eng. Res. Des., 90, 622-632.

Munin, A. \& EDWARdS-LÉvy, F. (2011): Encapsulation of natural polyphenolic compounds; a review. Pharmaceutics, 3, 793-829.

Paini, M., Aliakbarian, B., Casazza, A.A., Lagazzo, A., Botter, R. \& Perego, P. (2015): Microencapsulation of phenolic compounds from olive pomace using spray drying: A Study Of Operative Parameters. LWT - Food Sci. Technol., 62, 177-186.

Paz, R., García, P. \& Fredes, C. (2017): Drying and preservation of polyphenols. -in: Cuevas-Valenzuela, J., Vergara-Salinas, J.R. \& PÉrez-Correa, J.R. (Eds) Advances in technologies for producing food-relevant polyphenols. CRC Press, Boca Raton, USA, p. 335. 
Quirino Lacerda, E.C., De Araújo Calado, V.M., Monteiro, M., Finotelli, P.V., Guedes Torres, A. \& Perrone D. (2016): Starch, inulin and maltodextrin as encapsulating agents affect the quality and stability of jussara pulp microparticles. Carbohyd. Polym., 151, 500-510.

SaÉnz, C., TAPIA, S., Chávez, J. \& Robert, P. (2009): Microencapsulation by spray drying of bioactive compounds from cactus pear (Opuntia ficus-indica). Food Chem., 114, 616-622.

Tonon, R.V., Brabet, C. \& Hubinger, M.D. (2008): Influence of process conditions on the physicochemical properties of açai (Euterpe oleraceae Mart.) powder produced by spray drying. J. Food Eng., 88, 411-418.

Tonon, R.V., Brabet, C. \& Hubinger, M.D. (2010): Anthocyanin stability and antioxidant activity of spray-dried açai (Euterpe oleracea Mart.) juice produced with different carrier agents. Food Res. Int., 43, 907-914.

Tupuna, D.S., Paese, K., Stanisçuaski Guterres, S., Jablonski, A., Hickmann Flôres, S. \& De Oliveira Rios, A. (2018): Encapsulation efficiency and thermal stability of norbixin microencapsulated by spray-drying using different combinations of wall materials. Ind. Crop. Prod., 111, 846-855.

Urzúa, C., González, E., Dueik, V., Bouchon, P., Giménez, B. \& Robert, P. (2017): Olive leaves extract encapsulated by spray-drying in vacuum fried starch-gluten doughs. Food Bioprod. Process., 106, 171-180.

Vidović, S.S., Vladić, J.Z., VAŠTaG, Ž.G., Zeković, Z.P. \& Popović, LJ.M. (2014): Maltodextrin as a carrier of health benefit compounds in Satureja montana dry powder extract obtained by spray drying technique. Powder Technol., 258, 209-215.

Yousefi, S., EMAm-DJomen, Z. \& Mousavi, S.M. (2011): Effect of carrier type and spray drying on the physicochemical properties of powdered and reconstituted pomegranate juice (Punica granatum L.). J. Food Sci. Tech., 48, $677-684$. 